\title{
Temperature might increase the hospital admission risk for rheumatoid arthritis patients in Anqing, China: a time-series study
}

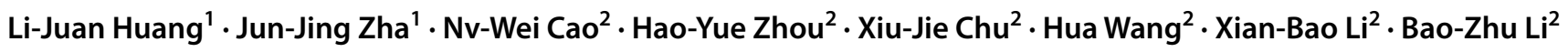

Received: 23 March 2021 / Revised: 13 October 2021 / Accepted: 13 October 2021 / Published online: 31 October 2021

(c) ISB 2021

\begin{abstract}
Temperature has been studied in relation to many health outcomes. However, few studies have explored its effect on the risk of hospital admission for rheumatoid arthritis (RA). A distributed lag non-linear model (DLNM) was used to analyze associations between mean temperature, diurnal temperature range (DTR), temperature change between neighboring days (TCN), and daily admissions for RA from 2015 to 2019 in Anqing, China. Subgroup analyses based on age, gender, rheumatoid factors, and admission route were performed. In total, 1456 patients with RA were hospitalized. Regarding the cumulative-lag effects of extreme cold temperature (5th percentile $=3^{\circ} \mathrm{C}$ ), the risks of admissions for RA were increased and highest at lag $0-11(\mathrm{RR}=2.68,95 \% \mathrm{CI}: 1.23-5.86)$. Exposing to low $\left(5\right.$ th percentile $\left.=1.9^{\circ} \mathrm{C}\right)$ and high $\left(95\right.$ th percentile $\left.=14.2^{\circ} \mathrm{C}\right) \mathrm{DTRs}$ both had increased risks of RA admission, with highest RRs of 1.40 (95\% CI: 1.03-1.91) and 1.24 (95\% CI: 1.0-1.53) at lag 0 day, respectively. As for TCN, the marginal risk of admission in RA patients was found when exposed to high TCN (95th percentile $\left.=2.9^{\circ} \mathrm{C}\right)$ with the largest single-day effect at lag $10(\mathrm{RR}=1.11,95 \% \mathrm{CI}: 1.01-1.23)$. In subgroup analyses, females were more susceptible to extreme cold temperature, low and high DTRs, and high TCN. In regard to extreme cold temperature, significant risk of hospital admission in females only appeared at lag 2 (RR $=1.48,95 \% \mathrm{CI}: 1.02-2.15)$ and lag 0-2 ( $R R=2.35,95 \% \mathrm{CI}: 1.11-4.95)$. It is clear that $\mathrm{RA}$ patients exposed to changing temperature may increase risks of admission.
\end{abstract}

Keywords Temperature $\cdot$ Rheumatoid arthritis $\cdot$ Hospital admission $\cdot$ DLNM $\cdot$ Time series

\section{Introductions}

Rheumatoid arthritis (RA) is an autoimmune disease, which troubles patients with pain and swelling in multiple joints (Cross et al. 2014). It affects $0.5-1 \%$ of the adult population (Scott et al. 2010), and commonly occurred in people aged 40-70 (Lee and Weinblatt 2001). Previous studies have demonstrated that prevalence and annual incidence of RA increased from 1990 to 2017 (Safiri et al. 2019). Besides, the number of crude disability adjusted of life years of RA patients increased by 25\% from 1990 to 2013 (Moradi-Lakeh et al. 2017). However, the causes for RA progression remain

Bao-Zhu Li

lbz88730@163.com

1 Medical Department, The Affiliated Anqing Hospital of Anhui Medical University, Anqing, Anhui, China

2 Department of Epidemiology and Biostatistics, School of Public Health, Anhui Medical University, Hefei 230032, Anhui, China unclear. It is generally believed that genetic factors (Karami et al. 2019; Constantin et al. 2001) and environmental factors, such as smoking (Liu et al. 2019b), infection (Arleevskaya et al. 2018), and microbiota (Zhang et al. 2015), might affect the progression. Previous studies have shown that air pressure and seasonal changes have harmful effects on disease activity and joints of RA (Terao et al. 2014; Mori et al. 2019). Thus, the fluctuant meteorological factors have attracted much attention.

Temperature, as a fluctuant environmental factor, has been studied in relation to many health outcomes (Malig et al. 2019; Schreier et al. 2013; Wang et al. 2021). Evidence have shown that RA was particularly sensitive to weather fluctuations, including altering temperature. Rheumatic disorders were reported to be correlated with the mean temperature (Patberg and Rasker 2004; Vergés et al. 2004). Joint pain is a common clinical manifestation in patients with RA, and the relationship between joint pain and temperature has been reported in previous studies. As early as the 1990s, Daniela and Abraham found that 
a change in the weather could exacerbate the symptoms of arthritis in most patients, and temperature was found to have a positive effect on pain (Guedj and Weinberger 1990). At the beginning of the twentieth century, Strusberg et al. (2002) followed up 82 RA patients, and the results showed that these patients were sensitive to the changes in temperature, and low temperature had a negative impact on their pain. Hamida reported that with a decrease in temperature in the winter, RA patients were more likely to experience pain in their joints (Azzouzi and Ichchou 2020). However, inconsistent results for the association between RA and temperature were demonstrated. Neogi et al. (2014) suggested that high temperature was related to the higher risk of pain. But Dorleijn et al. (2014) failed to found the association between temperature and pain. In a comprehensive systematic review conducted by Beukenhorst et al. (2020), no link or opposite associations between temperatures and RA pain were found in different studies, and potential effects in different directions of temperature appeared in different populations. Furthermore, Elcik et al. (2020) stated distinguishing results noted for RA, that warmer air masses contributed to the greatest number of emergency room visits, while colder air masses led to the fewest. Taken together, these findings show that changes in temperature might be associated with the risk of development or deterioration of RA.

Therefore, it is worthwhile to explore the relationship between changes in temperature and hospital admissions for RA. By understanding the impact of temperature changes on the risk of admission of patients with RA, timely measures can be taken to manage and alleviate the deterioration of the disease caused by temperature changes. Therefore, we conducted a time-series study to investigate the association between changing temperature metrics and hospital admissions for RA in Anqing, China, and to assess the risk of hospital admissions for RA.

\section{Material and methods}

\section{Study area}

Anqing $\left(30.52^{\circ} \mathrm{N}, 117.05^{\circ} \mathrm{E}\right)$ is a prefecture level city in in the southwest of Anhui Province, China, with a total area of $13,589.99 \mathrm{~km}^{2}$ and a permanent resident population of 4.723 million. Anqing is located in the northern subtropical humid climate zone, with obvious monsoons, four distinct seasons, a humid climate, and sufficient sunlight. The total amount of solar radiation is $112-117 \mathrm{kcal} / \mathrm{cm}^{2}$, and the annual average temperature is $14.5-16.6{ }^{\circ} \mathrm{C}$, which is slightly lower in the autumn than in the spring (http://www.anqing.gov.cn/zjaq/ zrhj/index.html).

\section{Data collection}

Daily admission data of patients with RA, including data on basic information, rheumatoid factors (RF) and home address of RA patients, admission date, and admission reasons, from January 1, 2015 to December 31, 2019, were obtained from Anqing Municipal Hospital. All patients were diagnosed as RA by rheumatologists according to the RA classification criteria revised by the American College of Rheumatology (Arnett et al. 1988). Cases from outside Anqing were excluded from this study based on home address of the patients.

Daily meteorological information, including data on relative humidity $(\mathrm{RH})$ and maximum and minimum temperatures $\left({ }^{\circ} \mathrm{C}\right)$, was retrieved from the China Meteorological Data Network (http://data.cma.cn/). Daily mean temperature $\left({ }^{\circ} \mathrm{C}\right)$ was calculated based on maximum and minimum temperatures. Besides, diurnal temperature range (DTR) and temperature change between neighboring days (TCN), as important metrics evaluating the associations between temperature changes and human health, were also calculated (Vicedo-Cabrera et al. 2016; Zhang et al. 2018). DTR was the range subtracting the daily minimum temperature from the daily maximum temperature. TCN was the change by subtracting the mean temperature of the day from that of the previous day. Daily air quality data, including data on the mean daily concentrations of particulate matter with an aerodynamic diameter of $<10 \mu \mathrm{m}\left(\mathrm{PM}_{10}\right)$, particulate matter with an aerodynamic diameter of $<2.5 \mu \mathrm{m}\left(\mathrm{PM}_{2.5}\right)$, sulfur dioxide $\left(\mathrm{SO}_{2}\right)$, nitrogen dioxide $\left(\mathrm{NO}_{2}\right)$, carbon monoxide (CO), and ozone $\left(\mathrm{O}_{3}\right)$, were obtained from the National Environmental Monitoring Center of China (https://www. aqistudy.cn/historydata/). This study was approved by the Ethics Committee of the Anhui Medical University, China (approval no: 2020H007).

\section{Statistical analysis}

The correlations between meteorological parameters, air quality, and daily admissions for RA were assessed using Spearman rank correlation analysis. Daily admission for RA was considered a small-probability event and showed an approximate Poisson distribution. Previous studies have shown that different health events have a non-linear relationship with temperature and air quality (Wang et al. 2021; Marinaccio et al. 2019; Liu et al. 2019a). Environmental factors usually have a delay effect on a disease; hence, it is necessary to use a flexible statistical model to describe the additional time dimension of the exposure-outcome relationship (Gasparrini et al. 2010). A distributed lag non-linear model (DLNM) considers the potential non-linearity of the dose-response curve and the delayed effect of exposure on 
the results (Gasparrini 2014; Gasparrini and Leone 2014). In this study, combined with a quasi-Poisson generalized linear model, a DLNM was used to analyze the associations between meteorological factors, air pollution, and daily admissions for RA.

Based on the results of Spearman's correlation analysis, $\mathrm{RH}, \mathrm{PM}_{10}, \mathrm{PM}_{2.5}, \mathrm{SO}_{2}, \mathrm{NO}_{2}, \mathrm{CO}$, and $\mathrm{O}_{3}$, all with $P$ value $<0.05$, were included in the final regression model as confounding factors (Supplementary Fig. S1). After model debugging and fitting, the final models for three temperature variables evaluating the association between temperature and RA admissions in Anqing were as follow:

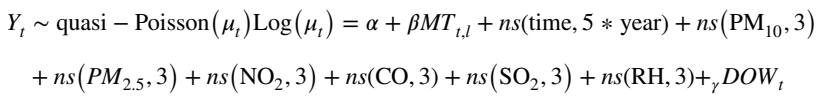

In this model, $t$ represents the number of observation days; $\mu_{t}$ is the number of RA cases admitted on day $t ; \alpha$ is the intercept of the model, which is a constant; $m t$ represents the daily mean temperature; DTR and TCN are two kinds of temperature changes; $\beta$ is the matrix coefficient of $t m ; l$ is the lag days; and $n s$ denotes the natural cubic spline of this model. Time is the observation days (1-1826 days), which was used to control for the time-varying factor (Bhaskaran et al. 2013). $D O W$ is a dummy variable in this model to control confounding effect of the day of week. $\gamma$ is the regression coefficient of $D O W$. Three degrees of freedom (dfs) were used to adjust for the confounding effect of relative humidity and air pollutions in this model. The quasi-Poisson Akaike information criterion (Q-AIC) was used to assess the model fit and ensure the optimal dfs for different variables (Gasparrini et al. 2010). Therefore, $5^{*}$ year is selected to control for the peak or valley of the temperature effect curve (Ma et al. 2013). Lags of 12, 12, and 10 days were set up to quantify the association between mean temperature, DTR, TCN, and admissions for RA with the lowest Q-AIC values (Supplementary Fig. S2).

Subgroup analyses according to gender and age were performed to identify susceptible population. Patients were divided into groups based on gender (male or female), age ( $<65$ years old or $\geq 65$ years old), RF index (positive or negative), and admission route (consulting room visits or emergency room visits). The relative risk (RR) and $95 \%$ confidence interval $(95 \%$ CI) were calculated to assess the lag risk and cumulative risk of admissions for RA.
In this model, as for mean temperature and DTR, the median annual temperature was selected as the first reference temperature. Then, the minimum RR is obtained by model prediction, and this temperature was deemed as the most suitable temperature and considered the reference temperature. As for $\mathrm{TCN}, 0^{\circ} \mathrm{C}$ was considered the reference temperature (Cheng et al. 2016). The 5th percentile of annual temperature was considered the extreme cold temperature, and the 95th percentile of annual temperature was considered the extreme hot temperature ( $\mathrm{Li}$ et al. 2017; Tobias et al. 2012; Zhao et al. 2019). The effect of very high temperature and very low temperature and the cumulative effect of the later lag on hospital admissions for RA were assessed. The packages "dlnm," "splines," and "ggplot2" in the R software version 4.0.3 were used for model analysis and result visualization. In this study, a $P$ value $<0.05$ was considered statistically significant.

\section{Sensitivity analysis}

Sensitivity analysis was conducted to evaluate the robustness of the model by changing dfs for ns, including time variable (5-7 dfs) and air pollutant variables (3-5 dfs). If no significant changes were found in the adjusted risk estimate of RA admissions, the model was considered stable.

\section{Result}

\section{Data description}

Basic information, rheumatoid factors (RF), and admission reasons of RA patients are shown in Table 1. In total, 1456 patients with RA, comprising 1053 (72.32\%) females and 403 (27.68\%) males, were hospitalized in Anqing from 2015 to 2019 . Among all patients, $545(37.43 \%)$ were aged below 65 years, and the remaining $911(62.57 \%)$ patients were aged 65 years and above; the mean age of the study population was 58.71 years. Of all patients, $1165(80.01 \%)$ were detected with positive RF, while 291 (19.99\%) with negative RF. The main reason for hospitalization of RA patients was pejorative joint pain accounting for $84.62 \%$, followed with pneumonia (9.20\%) and regular drug injections (5.98\%). In addition, the data on daily meteorological parameters and air quality are shown in Table 2 . The daily counts of admissions for RA ranged from 0 to 8 , with the maximum count on September 16, 2019. In Anqing City, the mean temperature was $17.29^{\circ} \mathrm{C}$ (from -4.8 to $33.6^{\circ} \mathrm{C}$ ), the mean DTR was $7.66^{\circ} \mathrm{C}$ (from 0.6 to $18.4^{\circ} \mathrm{C}$ ), and the mean $\mathrm{TCN}$ was $0^{\circ} \mathrm{C}$ (from -11.6 to $6.4^{\circ} \mathrm{C}$ ). The time-series distributions of total admissions for RA and the minimum, maximum, and mean temperatures from January 1, 2015 to December 31, 2019 are presented in Fig. 1. The average $\mathrm{PM}_{2.5}, \mathrm{PM}_{10}, \mathrm{SO}_{2}, \mathrm{NO}_{2}$, 
Table 1 Basic information, rheumatoid factors (RF), and admission reasons of RA patients

\begin{tabular}{llc}
\hline Characteristics & $\begin{array}{l}\text { Number of } \\
\text { patients }\end{array}$ & Percentage (\%) \\
\hline Gender & & \\
$\quad$ Male & 403 & 27.68 \\
$\quad$ Female & 1053 & 72.32 \\
Age (in years) & & \\
$\quad<65$ & 545 & 37.43 \\
$\quad \geq 65$ & 911 & 62.57 \\
RF index & & \\
RF positive & 1165 & 80.01 \\
RF negative & 291 & 19.99 \\
Admission route & & \\
Consulting room visit & 1150 & 78.98 \\
Emergency room visit & 306 & 21.02 \\
Reason for hospitalization & & \\
Exacerbation of joint pain & 1232 & 84.62 \\
Pneumonia & 134 & 9.20 \\
Regular drug injections & 87 & 5.98 \\
Fever & 54 & 3.71 \\
Cough & 37 & 2.54 \\
Gastrointestinal disease & 12 & 0.82 \\
Total & 1456 & 100.00 \\
\hline
\end{tabular}

$\mathrm{CO}$, and $\mathrm{O}_{3}$ levels were $50.43 \mu \mathrm{g} / \mathrm{m}^{3}, 70.52 \mu \mathrm{g} / \mathrm{m}^{3}, 14.33 \mu \mathrm{g} /$ $\mathrm{m}^{3}, 32.34 \mu \mathrm{g} / \mathrm{m}^{3}, 0.79 \mu \mathrm{g} / \mathrm{m}^{3}$, and $86.01 \mu \mathrm{g} / \mathrm{m}^{3}$, respectively.

\section{The association between daily mean temperature and daily RA admission in Anqing}

Supplementary Fig. S3A and Fig. A2 and B present the exposure-response relationship between mean temperature and the risk of hospital admissions for RA at various lag days. Patients with RA exposing to low environmental temperature were found to have an increased risk of admission.

The model showed that the risk of admission in patients with RA was the lowest when the mean temperature is $-4.5^{\circ} \mathrm{C}$. Therefore, this temperature was regarded as the reference temperature. The single-day lag and cumulativelag associations of extreme heat temperature (95th percentile $=30^{\circ} \mathrm{C}$ ) and extreme cold temperature (5th percentile $=3^{\circ} \mathrm{C}$ ) with hospital admissions for RA are presented in Table 3. On day 1, the single-day lags of extreme cold temperature and extreme heat temperature showed significant differences according to hospital admissions for RA with RRs of $=2.20$ (95\% CI: 1.14-4.21) and 3.46 (95\% CI: 1.31-9.15), respectively. Regarding the cumulative-lag association, the risk of admission for RA related to extreme cold temperature increased from lag $0-1(\mathrm{RR}=1.99,95 \% \mathrm{CI}$ : 1.05-3.77) to lag 0-3 (RR $=2.23,95 \%$ CI: $1.19-4.18)$ and from lag $0-8(\mathrm{RR}=2.16,95 \% \mathrm{CI}: 1.03-4.54)$ to lag $0-12$ $(\mathrm{RR}=2.59,95 \% \mathrm{CI}: 1.13-5.90)$, with the highest risk at lag $0-11(\mathrm{RR}=2.68,95 \% \mathrm{CI}: 1.23-5.86)$. As for extreme heat temperature, only at lag $0-2(\mathrm{RR}=3.29,95 \%$ CI: $1.17-9.30)$, the risk of the hospital admission for RA was significant. Figure 3A shows the visual cumulative-lag associations

Table 2 The characteristics of RA admissions and daily meteorological and air quality data in Anqing from 2015 to 2019

\begin{tabular}{|c|c|c|c|c|c|c|c|c|}
\hline \multirow[t]{2}{*}{ Variables } & \multirow[t]{2}{*}{ Mean \pm SD } & \multicolumn{7}{|l|}{ Centiles } \\
\hline & & Min & 0.05 & 0.25 & 0.50 & 0.75 & 0.95 & Max \\
\hline \multicolumn{9}{|l|}{ Meteorology measure } \\
\hline Mean temperature $\left({ }^{\circ} \mathrm{C}\right)$ & $17.29 \pm 8.92$ & -4.80 & 2.90 & 9.20 & 18.20 & 24.80 & 30.40 & 33.60 \\
\hline Maximum temperature $\left({ }^{\circ} \mathrm{C}\right)$ & $21.55 \pm 0.40$ & -2.00 & 5.73 & 13.80 & 22.95 & 29.20 & 34.90 & 40.00 \\
\hline Minimum temperature $\left({ }^{\circ} \mathrm{C}\right)$ & $13.90 \pm 8.83$ & -10.00 & -0.40 & 6.20 & 14.65 & 21.60 & 26.90 & 30.00 \\
\hline Diurnal temperature range $\left({ }^{\circ} \mathrm{C}\right)$ & $7.66 \pm 3.71$ & 0.60 & 1.90 & 4.80 & 7.40 & 10.50 & 14.20 & 18.40 \\
\hline $\begin{array}{l}\text { Temperature change between } \\
\text { neighboring days }\left({ }^{\circ} \mathrm{C}\right)\end{array}$ & $0.00 \pm 0.20$ & -11.60 & -3.90 & -1.00 & 0.20 & 1.30 & 2.90 & 6.40 \\
\hline Relative humidity (\%) & $76.47 \pm 13.70$ & 32.00 & 51.00 & 68.00 & 78.00 & 88.00 & 96.00 & 100.00 \\
\hline \multicolumn{9}{|l|}{ Pollutant concentration } \\
\hline $\mathrm{PM}_{2.5}(\mu \mathrm{g} / \mathrm{m} 3)$ & $50.43 \pm 33.03$ & 4.00 & 15.00 & 28.00 & 42.00 & 63.00 & 115.00 & 269.00 \\
\hline $\mathrm{PM}_{10}(\mu \mathrm{g} / \mathrm{m} 3)$ & $70.52 \pm 40.00$ & 9.00 & 24.00 & 42.00 & 62.00 & 89.00 & 149.30 & 367.00 \\
\hline $\mathrm{SO}_{2}(\mu \mathrm{g} / \mathrm{m} 3)$ & $14.33 \pm 7.39$ & 4.00 & 6.00 & 9.00 & 13.00 & 17.00 & 28.00 & 72.00 \\
\hline $\mathrm{NO}_{2}(\mu \mathrm{g} / \mathrm{m} 3)$ & $32.34 \pm 16.19$ & 6.00 & 14.00 & 20.00 & 28.00 & 41.00 & 65.00 & 113.00 \\
\hline $\mathrm{CO}(\mu \mathrm{g} / \mathrm{m} 3)$ & $0.79 \pm 0.43$ & 0.10 & 0.40 & 0.50 & 0.70 & 0.90 & 1.50 & 5.10 \\
\hline $\mathrm{O}_{3}(\mu \mathrm{g} / \mathrm{m} 3)$ & $86.01 \pm 40.25$ & 18.00 & 31.00 & 54.00 & 80.00 & 112.00 & 159.65 & 252.00 \\
\hline
\end{tabular}

$S D$ standard deviation; $P M_{2.5}$ particulate matter with an aerodynamic diameter of $<2.5 \mu \mathrm{m} ; P M_{10}$ particulate matter with an aerodynamic diameter of $<10 \mu \mathrm{m}$; $\mathrm{SO}_{2}$ sulfur dioxide; $\mathrm{NO}_{2}$ nitrogen dioxide; $\mathrm{CO}$ carbon monoxide; $\mathrm{O}_{3}$ ozone 
Fig. 1 The time-series distributions of mean temperature, diurnal temperature range, temperature change between neighboring days, and total RA admission in Anqing from 2015 to 2019. MT: mean temperature; DTR: diurnal temperature range; TCN: temperature change between neighboring days; TA: total admission
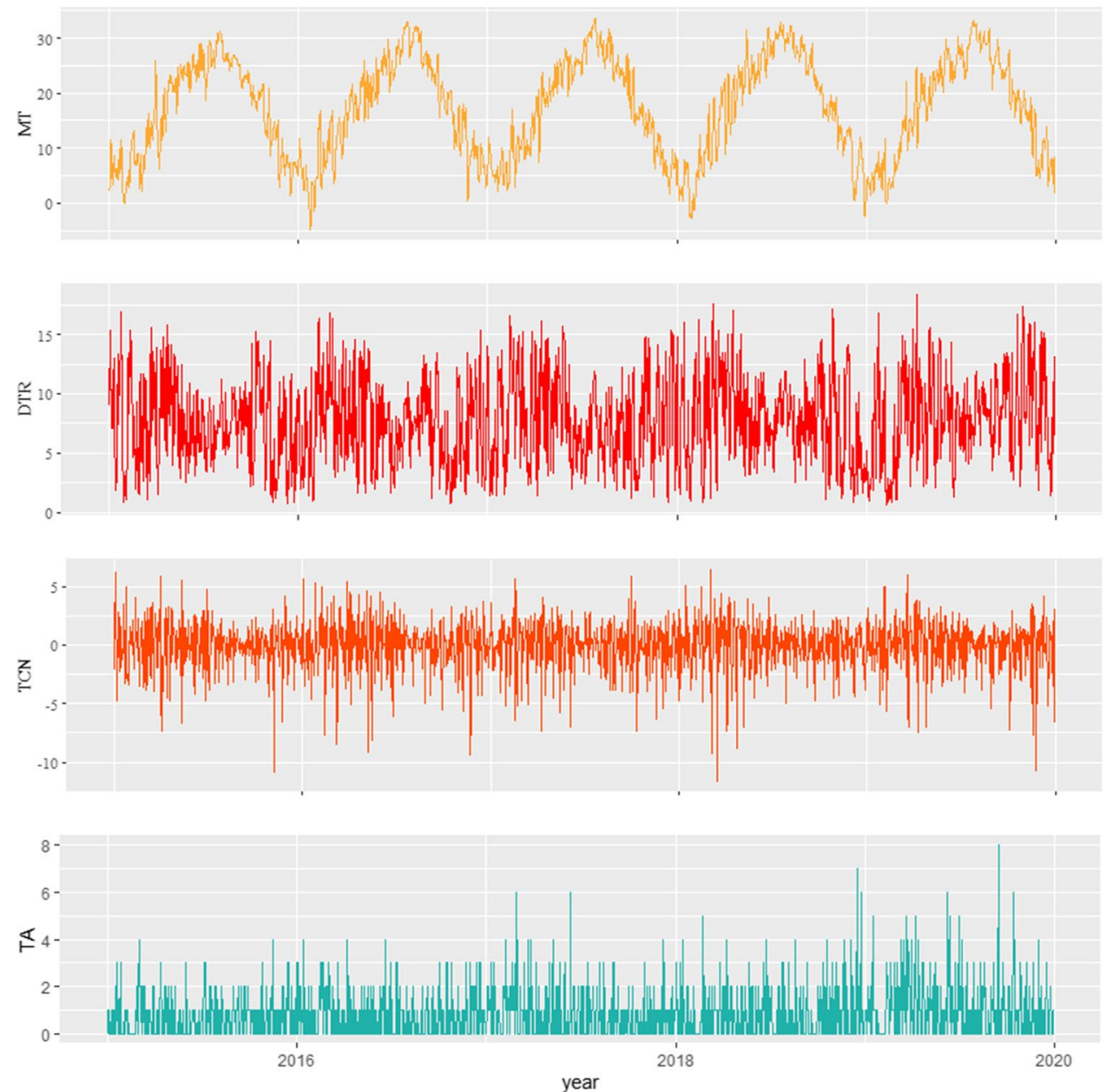

between RA admissions, extreme cold temperature, and extreme heat temperature.

The associations between extreme cold temperature and RA hospital admission in different subgroups are presented in Supplementary Table S1. No significant association was found between exposure to extreme cold temperature and the risk of admission in male patients with RA for single-day lag. However, as for multi-day lag, men had increased risks of hospital admission from lag 0-5 $(\mathrm{RR}=4.20,95 \% \mathrm{CI}$ : $1.01-17.50)$ to lag $0-12$ ( $\mathrm{RR}=8.33,95 \% \mathrm{CI}: 1.56-44.58)$, with the most robust risk at lag $0-10(\mathrm{RR}=9.83,95 \% \mathrm{CI}$ : 1.88-51.40). In female patients exposed to extreme cold temperature, a significant risk of hospital admission was seen only at lag $2(\mathrm{RR}=1.48,95 \% \mathrm{CI}: 1.02-2.15)$ with respect to single-day lag and lag $0-2(\mathrm{RR}=2.35,95 \% \mathrm{CI}$ : 1.11-4.95) with respect to cumulative lag. In patients with RA age $<65$ years, the exposure-lag-response association significantly increased at lag 0-9 $(\mathrm{RR}=3.75,95 \% \mathrm{CI}$ : 1.08-12.98) to lag $0-12(\mathrm{RR}=4.11,95 \% \mathrm{CI}: 1.10-15.28)$; however, the risk related to single-day lag was not significant. In the subgroup of hospitalized patients over 64 years old, no association was found according to both single-day lag and multi-day lag. At the subgroups of RF index, the single-lag effect was only significantly increased in RF-positive population at lag $9(\mathrm{RR}=1.16,95 \% \mathrm{CI}$ : $1.00-1.35)$, while not significant in RF-negative population. The cumulative RRs increased and got the peak at lag $0-11(\mathrm{RR}=2.61,95 \%$ CI: 1.11-6.14) for RF-positive group, while RR peaked at lag 0-3 for RF-negative group $(\mathrm{RR}=6.05,95 \% \mathrm{CI}$ : 1.28-28.66). Furthermore, regarding different admission routes, patients from consulting room had increased risk for hospitalization at extreme cold temperature $(\mathrm{RR}=1.19,95 \%$ CI: 1.01-1.40, lag 9). Regarding cumulative risks, hospitalized patients from consulting room and emergency room were both significantly affected with RRs $>1$.

\section{The association between DTR and daily RA admission in Anqing}

Supplementary Fig. S3B and Fig. 2C and D present the exposure-response relationship between DTR and the risk of hospital admissions for RA at various lag days. Exposing to low $\left(5\right.$ th percentile $\left.=1.9^{\circ} \mathrm{C}\right)$ and high $\left(95\right.$ th percentile $\left.=14.2^{\circ} \mathrm{C}\right)$ DTRs both had increased risks of RA admission. 
Fig. 2 The association between temperature changes and the risk of hospital admissions for RA. A The contour plot of exposure-lag-response risk of daily mean temperature for RA admission. B The overall cumulative exposure-response associations between daily mean temperature and admission risk for RA. C The contour plot of exposure-lag-response risk of DTR for RA admission. D The overall cumulative exposureresponse associations between DTR and admission risk for RA. E The contour plot of exposurelag-response risk of TCN for RA admission. F The overall cumulative exposure-response associations between TCN and admission risk for RA. DTR: diurnal temperature range; TCN: temperature change between neighboring days
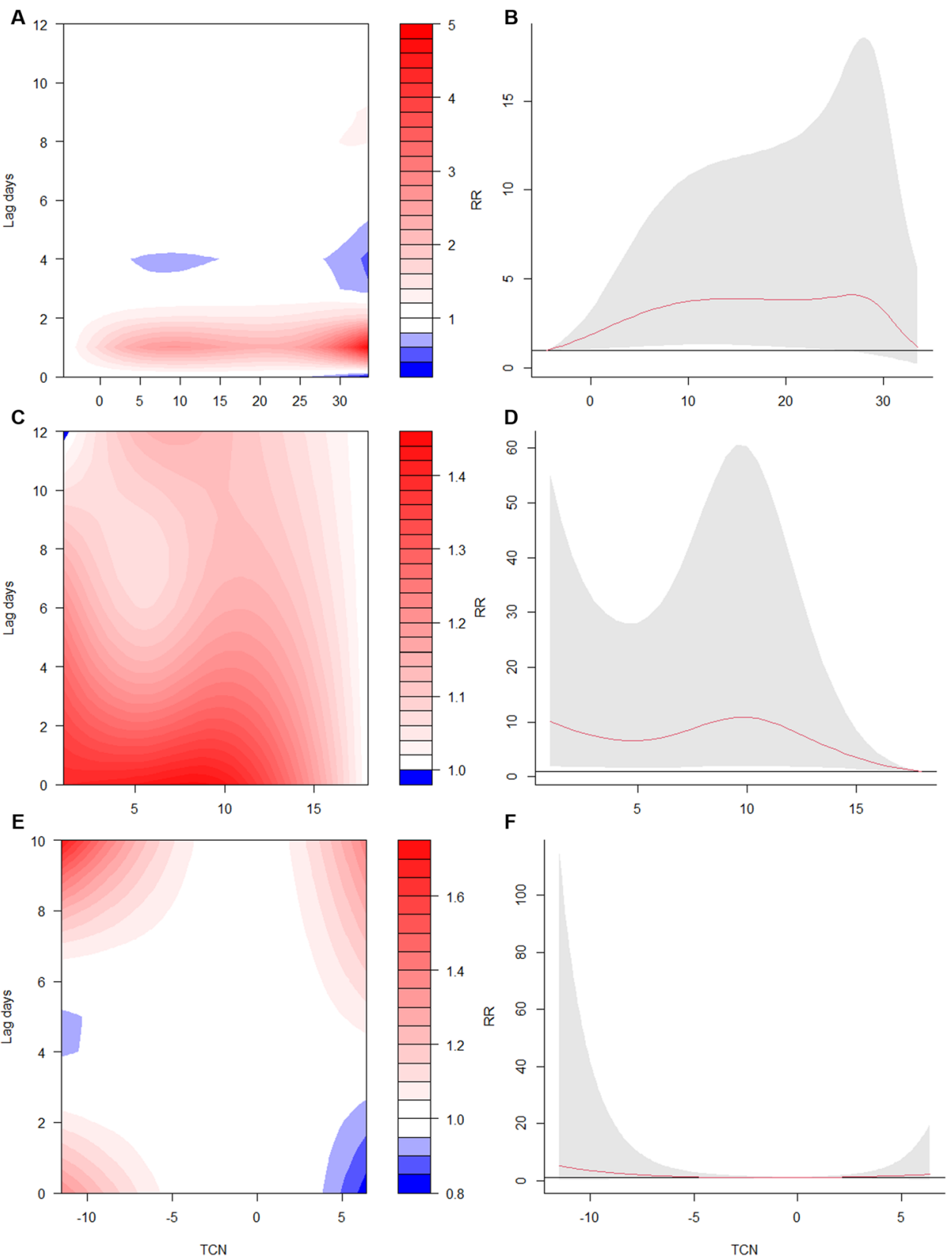

The DTR model showed that the risk of admission in RA patients was the lowest at DTR $=18^{\circ} \mathrm{C}$. Thus, it was considered the reference temperature. The single-day lag and cumulative-lag associations of low DTR (5th percentile $\left.=1.9^{\circ} \mathrm{C}\right)$ and high DTR $\left(95\right.$ th percentile $=14.2^{\circ} \mathrm{C}$ ) with hospital admissions for RA are presented in Table 4. On day 1 to day 5 , the single-day lags of low and high DTRs both showed increased risks for RA hospital admissions, with highest RRs of 1.40 (95\% CI: 1.03-1.91) and 1.24 (95\% CI: 1.01-1.53) at lag 0 day, respectively. The cumulative-lag effects of low and high DTRs are visualized in Fig. 3B. The risks of admission for RA related to low and high DTRs increased from lag $0-1$ to lag $0-12$ with the highest RRs of
8.58 (95\% CI: 1.82-40.48) and 5.03 (95\% CI: 1.60-15.86), respectively.

The associations between low DTR, high DTR, and RA hospital admission in different subgroups are presented in Supplementary Table S2 and S3. The subgroup analyses of different gender show that exposure to both low DTR and high DTR increased the hospitalized risk for female with highest value at lag $12(\mathrm{RR}=1.97,95 \% \mathrm{CI}$ : $1.03-3.75$; $\mathrm{RR}=2.02$, 95\% CI: 1.03-3.96). For the population from emergency room, the significant and lowest risk of hospitalization appeared at lag $6(\mathrm{RR}=1.45,95 \% \mathrm{CI}$ : $1.06-1.98)$. Besides, the cumulative risk for these patients was lowest at lag 0-4 (RR $=4.69,95 \% \mathrm{CI}: 1.15-19.11)$ and remained 
Table 3 The associations between extreme cold $\left(3^{\circ} \mathrm{C}\right)$, extreme heat $\left(30^{\circ} \mathrm{C}\right)$, and RA hospital admissions in Anqing from 2015 to 2019

\begin{tabular}{|c|c|c|c|c|c|}
\hline \multirow[t]{2}{*}{ Single-day } & \multicolumn{2}{|c|}{ Relative risk (95\% CI) } & \multirow[t]{2}{*}{ Multi-day } & \multicolumn{2}{|c|}{ Relative risk $(95 \% \mathrm{CI})$} \\
\hline & $\operatorname{Cold}\left(3^{\circ} \mathrm{C}\right)$ & Heat $\left(30^{\circ} \mathrm{C}\right)$ & & $\operatorname{Cold}\left(3^{\circ} \mathrm{C}\right)$ & Heat $\left(30^{\circ} \mathrm{C}\right)$ \\
\hline 0 & $0.91(0.40-2.04)$ & $0.58(0.16-2.08)$ & $0-0$ & $0.91(0.40-2.04)$ & $0.58(0.16-2.08)$ \\
\hline 1 & $2.20(1.14-4.21)^{*}$ & $3.46(1.31-9.15)^{*}$ & $0-1$ & $1.99(1.05-3.77)^{*}$ & $2.00(0.73-5.49)$ \\
\hline 2 & $1.32(0.95-1.84)$ & $1.65(0.99-2.76)$ & $0-2$ & $2.63(1.34-5.14)^{*}$ & $3.29(1.17-9.30)^{*}$ \\
\hline 3 & $0.85(0.64-1.12)$ & $0.80(0.52-1.23)$ & $0-3$ & $2.23(1.19-4.18)^{*}$ & $2.64(0.97-7.19)$ \\
\hline 4 & $0.81(0.63-1.05)$ & $0.73(0.49-1.09)$ & $0-4$ & $1.81(0.94-3.47)$ & $1.93(0.66-5.67)$ \\
\hline 5 & $0.93(0.79-1.08)$ & $0.89(0.70-1.13)$ & $0-5$ & $1.67(0.85-3.30)$ & $1.72(0.55-5.40)$ \\
\hline 6 & $1.04(0.88-1.22)$ & $1.06(0.83-1.34)$ & $0-6$ & $1.73(0.87-3.43)$ & $1.82(0.56-5.89)$ \\
\hline 7 & $1.11(0.92-1.33)$ & $1.16(0.89-1.53)$ & $0-7$ & $1.91(0.95-3.86)$ & $2.12(0.63-7.17)$ \\
\hline 8 & $1.13(0.95-1.34)$ & $1.20(0.93-1.55)$ & $0-8$ & $2.16(1.03-4.54)^{*}$ & $2.54(0.70-9.27)$ \\
\hline 9 & $1.12(0.98-1.28)$ & $1.18(0.96-1.45)$ & $0-9$ & $2.42(1.11-5.27)^{*}$ & $3.00(0.76-11.81)$ \\
\hline 10 & $1.08(0.96-1.22)$ & $1.12(0.92-1.35)$ & $0-10$ & $2.62(1.19-5.75)^{*}$ & $3.35(0.81-13.91)$ \\
\hline 11 & $1.03(0.85-1.24)$ & $1.03(0.78-1.37)$ & $0-11$ & $2.68(1.23-5.86)^{*}$ & $3.45(0.80-14.95)$ \\
\hline 12 & $0.97(0.71-1.31)$ & $0.94(0.60-1.47)$ & $0-12$ & $2.59(1.13-5.90)^{*}$ & $3.24(0.67-15.66)$ \\
\hline
\end{tabular}

${ }^{*} P<0.05$
A

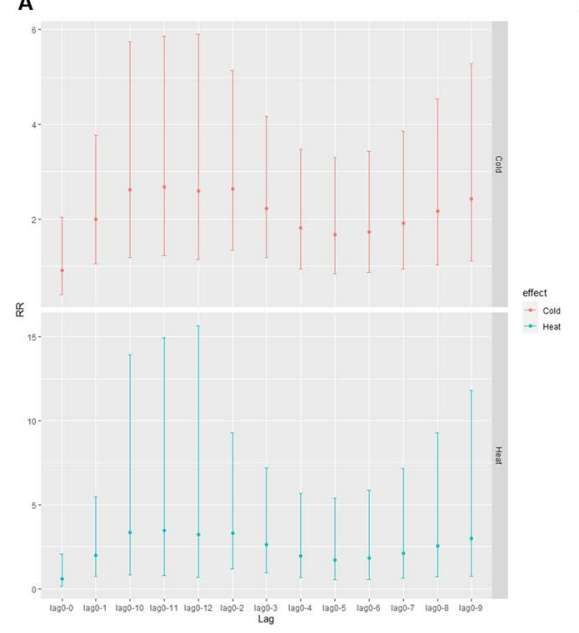

B

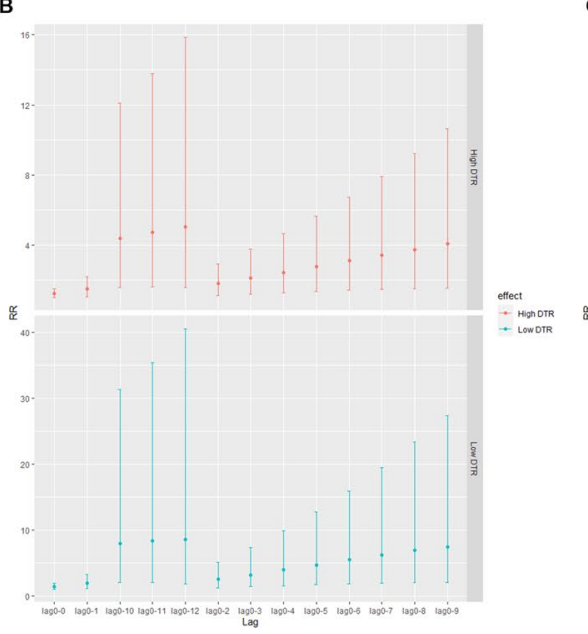

c

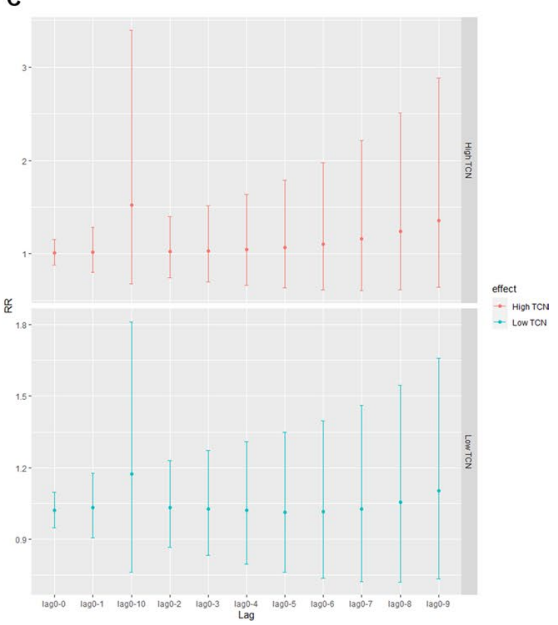

Fig. 3 The cumulative-lag associations of between temperature changes and RA hospital admissions. A The cumulative-lag RR of between extreme cold temperature $\left(3^{\circ} \mathrm{C}\right)$, extreme heat temperature $\left(30^{\circ} \mathrm{C}\right)$, and RA hospital admissions. B The cumulative-lag RR of between high DTR $\left(14.2^{\circ} \mathrm{C}\right)$, low DTR $\left(1.9^{\circ} \mathrm{C}\right)$, and RA hospital admissions. C The cumulative-lag RR of between high TCN $\left(2.9^{\circ} \mathrm{C}\right)$, low TCN $\left(-3.9^{\circ} \mathrm{C}\right)$, and RA hospital admissions. DTR: diurnal temperature range; TCN: temperature change between neighboring days; RR: relative risk; RR: relative risk significantly increased. Only the emergency room population had significantly increased risk of hospitalization at high DTR in both single and cumulative-lag days.

\section{The association between TCN and daily RA admission in Anqing}

Supplementary Fig. S3C and Fig. 2E and F present the exposure-response relationship between TCN and the risk of hospital admissions for RA at various lag days. Marginal association between TCN and RA admissions was found.
The marginal risk of admission in RA patients was found when exposed to high $\mathrm{TCN}\left(95\right.$ th percentile $\left.=2.9^{\circ} \mathrm{C}\right)$. The largest single-day effect of high TCN was observed at lag $10(\mathrm{RR}=1.11,95 \% \mathrm{CI}: 1.01-1.23)$ (Table 5). However, no significant cumulative effect of TCN was found (Fig. 3C). After stratifying by gender, adverse effects of high TCN were found on patients who aged $<65(\mathrm{RR}=1.22,95 \% \mathrm{CI}$ : 1.03-1.45, lag 9; RR=3.88, 95\% CI: 1.05-14.29, lag 0-10). Surprisingly, opposite results were found in the subgroup analyses of different admission routes. Increased risk for RA hospitalization was found in population from consulting 
Table 4 The associations between low DTR $\left(1.9^{\circ} \mathrm{C}\right)$, high DTR $\left(14.2^{\circ} \mathrm{C}\right)$, and RA hospital admissions in Anqing from 2015 to 2019

\begin{tabular}{|c|c|c|c|c|c|}
\hline \multirow[t]{2}{*}{ Single-day } & \multicolumn{2}{|c|}{ Relative risk $(95 \% \mathrm{CI})$} & \multirow[t]{2}{*}{ Multi-day } & \multicolumn{2}{|c|}{ Relative risk $(95 \% \mathrm{CI})$} \\
\hline & Low $\left(1.9^{\circ} \mathrm{C}\right)$ & $\operatorname{High}\left(14.2^{\circ} \mathrm{C}\right)$ & & Low $\left(1.9^{\circ} \mathrm{C}\right)$ & $\operatorname{High}\left(14.2^{\circ} \mathrm{C}\right)$ \\
\hline 0 & $1.40(1.03-1.91)^{*}$ & $1.24(1.01-1.53)^{*}$ & $0-0$ & $1.40(1.03-1.91)^{*}$ & $1.24(1.01-1.53)^{*}$ \\
\hline 1 & $1.36(1.07-1.72)^{*}$ & $1.22(1.04-1.43)^{*}$ & $0-1$ & $1.90(1.11-3.27)^{*}$ & $1.52(1.05-2.18)^{*}$ \\
\hline 2 & $1.31(1.09-1.57)^{*}$ & $1.20(1.05-1.36)^{*}$ & $0-2$ & $2.50(1.23-5.08)^{*}$ & $1.81(1.12-2.94) *$ \\
\hline 3 & $1.27(1.09-1.48)^{*}$ & $1.17(1.05-1.31)^{*}$ & $0-3$ & $3.17(1.38-7.30)^{*}$ & $2.13(1.20-3.77)^{*}$ \\
\hline 4 & $1.23(1.06-1.43)^{*}$ & $1.15(1.03-1.29)^{*}$ & $0-4$ & $3.91(1.55-9.83) *$ & $2.45(1.29-4.66)^{*}$ \\
\hline 5 & $1.20(1.02-1.41)^{*}$ & $1.13(1.01-1.28)^{*}$ & $0-5$ & $4.67(1.72-12.68)^{*}$ & $2.78(1.37-5.64)^{*}$ \\
\hline 6 & $1.16(0.98-1.38)$ & $1.12(0.99-1.26)$ & $0-6$ & $5.44(1.86-15.90)^{*}$ & $3.10(1.43-6.72)^{*}$ \\
\hline 7 & $1.14(0.96-1.34)$ & $1.11(0.98-1.25)$ & $0-7$ & $6.18(1.96-19.50)^{*}$ & $3.43(1.48-7.93)^{*}$ \\
\hline 8 & $1.11(0.95-1.29)$ & $1.09(0.98-1.22)$ & $0-8$ & $6.86(2.01-23.37)^{*}$ & $3.75(1.52-9.24)^{*}$ \\
\hline 9 & $1.09(0.94-1.26)$ & $1.09(0.97-1.21)$ & $0-9$ & $7.46(2.04-27.32)^{*}$ & $4.07(1.56-10.63)^{*}$ \\
\hline 10 & $1.07(0.91-1.26)$ & $1.08(0.96-1.22)$ & $0-10$ & $7.96(2.03-31.25)^{*}$ & $4.40(1.60-12.11)^{*}$ \\
\hline 11 & $1.05(0.85-1.29)$ & $1.07(0.92-1.25)$ & $0-11$ & $8.34(1.97-35.37)^{*}$ & $4.72(1.62-13.77)^{*}$ \\
\hline 12 & $1.03(0.79-1.35)$ & $1.07(0.88-1.30)$ & $0-12$ & $8.58(1.82-40.48)^{*}$ & $5.03(1.60-15.86)^{*}$ \\
\hline
\end{tabular}

$D T R$ diurnal temperature range ${ }^{*} P<0.05$

room $(\mathrm{RR}=1.20,95 \% \mathrm{CI}: 1.01-1.42)$, while decreased risk was found in population from emergency room $(\mathrm{RR}=0.77$, 95\% CI: 0.62-0.96) (Supplementary Table S4).

\section{Sensitivity analysis}

The sensitivity analysis was conducted by changing the dfs for the time variable (5-7 dfs) and other environmental factors (3-5 dfs). When controlling the dfs of variables in the mean temperature model, no significant changes were appeared (Supplementary Fig. S4 and S5). Besides, after adjusting the dfs in the DTR model, there were slightly changes in the results without statistical significance (Supplementary Fig. S6 and S7). With changing dfs of variables, the effects of TCN on RA admissions did not sharply change and appeared stable tendency with the original one (Supplementary Fig. S8 and S9). The results of sensitivity analyses indicate robust association between temperature and hospital admissions for RA.

\section{Discussion}

To our knowledge, few studies have evaluated the association between temperature and the risk of admission for RA. In this study, temperature changes were considered factors that might increase the risk of admission for RA with significantly delayed effects. According to the results of the subgroup analysis, males were more likely to be vulnerable in a low-temperature environment and admitted to the
Table 5 The associations between low TCN $\left(-3.9^{\circ} \mathrm{C}\right)$, high TCN $\left(2.9^{\circ} \mathrm{C}\right)$, and RA hospital admissions in Anqing from 2015 to 2019

\begin{tabular}{lllllll}
\hline \multirow{2}{*}{ Single-day } & \multicolumn{2}{l}{ Relative risk $(95 \% \mathrm{CI})$} & \multirow{2}{l}{ Multi-day } & \multicolumn{2}{l}{ Relative risk $(95 \% \mathrm{CI})$} \\
\cline { 2 - 3 } & Low $\left(-3.9^{\circ} \mathrm{C}\right)$ & High $\left(2.9^{\circ} \mathrm{C}\right)$ & & & Low $\left(-3.9^{\circ} \mathrm{C}\right)$ & High $\left(2.9^{\circ} \mathrm{C}\right)$ \\
\hline 0 & $1.00(0.90-1.13)$ & $0.98(0.88-1.09)$ & $0-0$ & & $1.00(0.90-1.13)$ & $0.98(0.88-1.09)$ \\
1 & $1.00(0.91-1.09)$ & $0.99(0.91-1.07)$ & $0-1$ & & $1.00(0.82-1.23)$ & $0.97(0.80-1.17)$ \\
2 & $0.99(0.92-1.07)$ & $0.99(0.93-1.06)$ & $0-2$ & & $1.00(0.76-1.31)$ & $0.96(0.75-1.23)$ \\
3 & $0.99(0.92-1.07)$ & $1.00(0.93-1.07)$ & $0-3$ & & $0.99(0.71-1.38)$ & $0.96(0.71-1.29)$ \\
4 & $0.99(0.92-1.07)$ & $1.01(0.93-1.08)$ & $0-4$ & & $0.98(0.66-1.44)$ & $0.96(0.68-1.36)$ \\
5 & $0.99(0.92-1.07)$ & $1.02(0.94-1.10)$ & $0-5$ & & $0.97(0.62-1.51)$ & $0.98(0.66-1.45)$ \\
6 & $1.00(0.93-1.08)$ & $1.03(0.96-1.11)$ & $0-6$ & & $0.97(0.59-1.59)$ & $1.01(0.65-1.57)$ \\
7 & $1.01(0.95-1.08)$ & $1.05(0.98-1.12)$ & $0-7$ & & $0.98(0.57-1.69)$ & $1.06(0.65-1.73)$ \\
8 & $1.03(0.96-1.10)$ & $1.07(1.00-1.14)^{*}$ & $0-8$ & & $1.01(0.56-1.82)$ & $1.13(0.66-1.93)$ \\
9 & $1.04(0.97-1.12)$ & $1.09(1.01-1.18)^{*}$ & $0-9$ & & $1.05(0.56-1.97)$ & $1.23(0.69-2.18)$ \\
10 & $1.06(0.97-1.17)$ & $1.11(1.01-1.23)^{*}$ & $0-10$ & & $1.11(0.57-2.18)$ & $1.36(0.74-2.52)$ \\
\hline
\end{tabular}

TCN temperature change between neighboring days ${ }^{*} P<0.05$ 
hospital for further treatment. Moreover, patients with RA aged $<65$ years had a higher risk of admission in the cold environment than those aged $\geq 65$ years.

This study found a significant association between low temperature and admission for RA. Based on their experiences in daily life, people have maintained an old belief that weather can affect joint pain. Previous studies have indicated that exposure to cold environments might be associated with a risk of musculoskeletal disorders, such as back and neck (Burström et al. 2013), and white fingers (Burström et al. 2010). In a Spanish study, 245 patients who visited the emergency room because of worsening pain due to RA were included (Abasolo et al. 2013). The patients' symptoms and weather conditions were analyzed using a case-crossover design, and the results indicated that a low mean temperature might worsen symptoms in patients with RA (Abasolo et al. 2013). Some study results have suggested that extreme changes in temperature might cause an inflammatory reaction that leads to adverse effect related to RA. Based on research results, some interesting ideas were put forward that extreme temperature changes may cause inflammatory reaction and adverse effect. For example, a decrease in temperature can increase $\mathrm{C}$-reactive protein, especially in the winter and spring (Sung 2006). The relationship between rapidly decreased temperature and increased IL-6 was significant with respect to the risk of cardiovascular disease (Schneider et al. 2008). Furthermore, sudden changes in temperature could affect the homeostasis of B and T lymphocytes, resulting in autoimmune disorders (Maes et al. 1994). These inflammatory factors play important roles not only in cardiovascular disease but also in RA development. In the Epidemiological Investigation of Rheumatoid Arthritis study, a case-control study based on Swedish population, increased risk of RA was found related to working in cold environments, with respect to both anticitrullinated protein antibody-positive and anticitrullinated protein antibodynegative RA (Zeng et al. 2017).

The subgroup analyses demonstrated that the lag effects of temperature changes were different between patients aged below 65 years and those aged $\geq 65$ years, and the effect of changes in temperature was significant in RA patients aged below 65 years. A previous study showed that the association between the worsening of RA symptoms and exposure to low temperatures was significant only in patients aged between 50 and 65 years (Abasolo et al. 2013), similar to our finding. A previous study reported that young people rated more pain (Lue et al. 2018), which may promote young RA patients hospitalized when they got the exacerbation of joint pain. The other opposite direction is that RA patients aged $\geq$ 65 who have the need to go to the hospital, but actually don't go for various reasons. High medical costs may prevent the elderly who cannot afford treatment (Zeng et al. 2021). They visit the hospital only when the pain becomes unbearable.
This might be a possible reason for the lag effect of low temperature. Furthermore, elderly patients might have other severe conditions; hence, the aggravation of RA symptoms caused by exposure to low temperatures might not get due attention, leading to lower hospitalization rates. The subgroup analysis according to gender indicated that the risk of admission for RA was higher in females with RA than in males with RA. Compared to males, females were more sensitive to pain (Fillingim et al. 2009), and when female patients feel pain due to temperature changes, they may go to the hospital for treatment.

There are some strengths to this study. First, this study evaluated the effects of temperature changes on the risk of admission for RA, considering possible lag effect using the DLNM model. Second, the RH and air quality indicators were included as confounding variables to assess the effects of temperature changes, which made our results more convincing. Third, subgroup analyses with respect to age, gender, RF index, and admission route of RA patients were performed to identify the risk of admission for RA in patients with different characteristics. We hope that our results can emphasize the need for considering the impact of temperature change on the health of patients with RA and reduce both the health and economic burdens of RA.

However, the study also has several limitations. As this was an ecological study, it was difficult to rule out the existence of ecological fallacy. Second, the data on admission for RA were collected from only one city, which cannot represent the data in other cities or regions. Third, the small samples of RA admission in Anqing City may affect the evaluation of the exposure-response lag association between temperature changes and RA admission. Furthermore, due to the lack of information on patient exposure, it was difficult to determine the patients' exposure to outdoor temperatures, which might bias the results.

\section{Conclusion}

In this study, we found the association between exposure to extreme cold temperature, low and high DTRs, low TCN, and admission risk of RA in Anqing, China. Furthermore, subgroup analyses indicated that male patients and patients younger than 65 years old had higher risk of hospitalized admissions. To avoid RA worsening, RA patients should pay more attention to their health and keep warm according to the temperature changes.

Supplementary Information The online version contains supplementary material available at https://doi.org/10.1007/s00484-021-02207-9.

Author contribution Li-Juan Huang: writing—original draft, project administration, resources. 
Nv-Wei Cao, Hao-Yue Zhou, and Xiu-Jie Chu: investigation, methodology.

Hua Wang and Xian-Bao Li: data curation, software.

Bao-Zhu Li: project administration, funding acquisition.

Funding This study was supported by the National Natural Science Foundation of China (81803310) and emergency research project of novel coronavirus infection of Anhui Medical University (YJGG202003).

Data availability The datasets generated during and/or analyzed during the current study are available from the corresponding author on reasonable request.

Code availability No applicable.

\section{Declarations}

Ethical approval This study has got the ethical approval from Anhui Medical University Ethics Committee (ethical approval number: 2020H007).

Consent to participate No applicable.

Competing interests The authors declare no competing interests.

\section{References}

Abasolo L, Tobías A, Leon L, Carmona L, Fernandez-Rueda JL, Rodriguez $\mathrm{AB}$ et al (2013) Weather conditions may worsen symptoms in rheumatoid arthritis patients: the possible effect of temperature. Reumatol Clin 9(4):226-228. https://doi.org/10.1016/j.reuma. 2012.09.006

Arleevskaya MI, Albina S, Larionova RV, Gabdoulkhakova AG, Lemerle J, Renaudineau Y (2018) Prevalence and incidence of upper respiratory tract infection events are elevated prior to the development of rheumatoid arthritis in first-degree relatives. Front Immunol 9:2771. https://doi.org/10.3389/fimmu.2018.02771

Arnett FC, Edworthy SM, Bloch DA, McShane DJ, Fries JF, Cooper NS et al (1988) The American Rheumatism Association 1987 revised criteria for the classification of rheumatoid arthritis. Arthritis Rheum 31(3):315-324. https://doi.org/10.1002/art. 1780310302

Azzouzi H, Ichchou L (2020) Seasonal and weather effects on rheumatoid arthritis: myth or reality? Pain Res Manag 2020:5763080. https://doi.org/10.1155/2020/5763080

Beukenhorst AL, Schultz DM, McBeth J, Sergeant JC, Dixon WG (2020) Are weather conditions associated with chronic musculoskeletal pain? Review of Results and Methodologies. Pain 161(4):668-683. https://doi.org/10.1097/j.pain.0000000000 001776

Bhaskaran K, Gasparrini A, Hajat S, Smeeth L, Armstrong B (2013) Time series regression studies in environmental epidemiology. Int J Epidemiol 42(4):1187-1195. https://doi.org/10.1093/ije/dyt092

Burström L, Järvholm B, Nilsson T, Wahlström J (2010) White fingers, cold environment, and vibration-exposure among Swedish construction workers. Scand J Work Environ Health 36(6):509-513. https://doi.org/10.5271/sjweh.3072

Burström L, Järvholm B, Nilsson T, Wahlström J (2013) Back and neck pain due to working in a cold environment: a cross-sectional study of male construction workers. Int Arch Occup Environ Health 86(7):809-813. https://doi.org/10.1007/s00420-012-0818-9
Cheng J, Xu Z, Zhao D, Xie M, Yang H, Wen L et al (2016) Impacts of temperature change on ambulance dispatches and seasonal effect modification. Int J Biometeorol 60(12):1863-1871. https://doi. org/10.1007/s00484-016-1173-4

Constantin A, Navaux F, Lauwers-Cancès V, Abbal M, van Meerwijk JP, Mazières B et al (2001) Interferon gamma gene polymorphism and susceptibility to, and severity of, rheumatoid arthritis. Lancet (london, England) 358(9298):2051-2052. https://doi.org/10.1016/ s0140-6736(01)07143-4

Cross M, Smith E, Hoy D, Carmona L, Wolfe F, Vos T et al (2014) The global burden of rheumatoid arthritis: estimates from the global burden of disease 2010 study. Ann Rheum Dis 73(7):1316-1322. https://doi.org/10.1136/annrheumdis-2013-204627/

Dorleijn DMJ, Luijsterburg PAJ, Burdorf A, Rozendaal RM, Verhaar JAN, Bos PK et al (2014) Associations between weather conditions and clinical symptoms in patients with hip osteoarthritis: a 2-year cohort study. Pain 155(4):808-813. https://doi.org/10. 1016/j.pain.2014.01.018

Elcik C, Fuhrmann CM, Sheridan SC, Mercer AE, Sherman-Morris K (2020) Relationship between synoptic weather type and emergency department visits for different types of pain across the Triangle region of North Carolina. Int J Biometeorol 64(11):18151823. https://doi.org/10.1007/s00484-020-01966-1

Fillingim RB, King CD, Ribeiro-Dasilva MC, Rahim-Williams B, Riley JL 3rd (2009) Sex, gender, and pain: a review of recent clinical and experimental findings. J Pain 10(5):447-485. https:// doi.org/10.1016/j.jpain.2008.12.001

Gasparrini A (2014) Modeling exposure-lag-response associations with distributed lag non-linear models. Stat Med 33(5):881-899. https://doi.org/10.1002/sim.5963

Gasparrini A, Leone M (2014) Attributable risk from distributed lag models. BMC Med Res Methodol 14:55. https://doi.org/10.1186/ 1471-2288-14-55

Gasparrini A, Armstrong B, Kenward MG (2010) Distributed lag non-linear models. Stat Med 29(21):2224-2234. https://doi.org/ 10.1002/sim.3940

Guedj D, Weinberger A (1990) Effect of weather conditions on rheumatic patients. Ann Rheum Dis 49(3):158-159. https://doi.org/ 10.1136/ard.49.3.158

Karami J, Aslani S, Jamshidi A, Garshasbi M, Mahmoudi M (2019) Genetic implications in the pathogenesis of rheumatoid arthritis; an updated review. Gene 702:8-16. https://doi.org/10.1016/j.gene. 2019.03.033

Lee DM, Weinblatt ME (2001) Rheumatoid arthritis. Lancet (london, England) 358(9285):903-911. https://doi.org/10.1016/s01406736(01)06075-5

Li Y, Ji C, Ju H, Han Y (2017) Impact of ambient temperature and atmospheric evaporation on the incidence of acute deep venous thrombosis in the northeast of China. Int Angiol 36(3):243-253. https://doi.org/10.23736/s0392-9590.16.03730-5

Liu G, Sun B, Yu L, Chen J, Han B, Liu B et al (2019a) Shortterm exposure to ambient air pollution and daily atherosclerotic heart disease mortality in a cool climate. Environ Sci Pollut Res Int 26(23):23603-23614. https://doi.org/10.1007/ s11356-019-05565-5

Liu X, Tedeschi SK, Barbhaiya M, Leatherwood CL, Speyer CB, Lu B et al (2019b) Impact and timing of smoking cessation on reducing risk of rheumatoid arthritis among women in the nurses' health studies. Arthritis Care Res 71(7):914-924. https://doi.org/10. 1002/acr.23837

Lue YJ, Wang H, Cheng KI, Chen CH, Lu YM (2018) Thermal pain tolerance and pain rating in normal subjects: gender and age effects. Eur J Pain 22(6):1035-1042. https://doi.org/10.1002/ejp. 1188

Ma W, Sun X, Song Y, Tao F, Feng W, He Y et al (2013) Applied mixed generalized additive model to assess the effect of temperature on 
the incidence of bacillary dysentery and its forecast. PLoS ONE 8(4):e62122. https://doi.org/10.1371/journal.pone.0062122

Maes M, Stevens W, Scharpé S, Bosmans E, De Meyer F, D’Hondt $P$ et al (1994) Seasonal variation in peripheral blood leukocyte subsets and in serum interleukin-6, and soluble interleukin-2 and -6 receptor concentrations in normal volunteers. Experientia 50(9):821-829. https://doi.org/10.1007/bf01956463

Malig BJ, Wu XM, Guirguis K, Gershunov A, Basu R (2019) Associations between ambient temperature and hepatobiliary and renal hospitalizations in California, 1999 to 2009. Environ Res 177:108566. https://doi.org/10.1016/j.envres.2019.108566

Marinaccio A, Scortichini M, Gariazzo C, Leva A, Bonafede M, De' Donato FK, et al (2019) Nationwide epidemiological study for estimating the effect of extreme outdoor temperature on occupational injuries in Italy. Environ Int 133(Pt A):105176. https://doi. org/10.1016/j.envint.2019.105176

Moradi-Lakeh M, Forouzanfar MH, Vollset SE, El Bcheraoui C, Daoud F, Afshin A et al (2017) Burden of musculoskeletal disorders in the Eastern Mediterranean Region, 1990-2013: findings from the Global Burden of Disease Study 2013. Ann Rheum Dis 76(8):1365-1373. https://doi.org/10.1136/annrh eumdis-2016-210146

Mori H, Sawada T, Nishiyama S, Shimada K, Tahara K, Hayashi H, et al. (2019) Influence of seasonal changes on disease activity and distribution of affected joints in rheumatoid arthritis. BMC Musculoskelet Disord. 20 (1):30. https://doi.org/10.1186/ s12891-019-2418-2

Neogi T, Chen C, Niu J, Chaisson C, Hunter DJ, Choi H et al (2014) Relation of temperature and humidity to the risk of recurrent gout attacks. Am J Epidemiol 180(4):372-377. https://doi.org/10.1093/ aje/kwu147.s

Patberg WR, Rasker JJ (2004) Weather effects in rheumatoid arthritis: from controversy to consensus. A Review J Rheumatol 31(7):1327-1334

Safiri S, Kolahi AA, Hoy D, Smith E, Bettampadi D, Mansournia MA et al (2019) Global, regional and national burden of rheumatoid arthritis 1990-2017: a systematic analysis of the Global Burden of Disease study 2017. Ann Rheum Dis 78(11):1463-1471. https:// doi.org/10.1136/annrheumdis-2019-215920

Schneider A, Panagiotakos D, Picciotto S, Katsouyanni K, Löwel $\mathrm{H}$, Jacquemin B et al (2008) Air temperature and inflammatory responses in myocardial infarction survivors. Epidemiology 19(3):391-400. https://doi.org/10.1097/EDE.0b013e31816a4325

Schreier N, Moltchanova E, Forsén T, Kajantie E, Eriksson JG (2013) Seasonality and ambient temperature at time of conception in term-born individuals-influences on cardiovascular disease and obesity in adult life. Int J Circumpolar Health 72:21466. https:// doi.org/10.3402/ijch.v72i0.21466

Scott DL, Wolfe F, Huizinga TW (2010) Rheumatoid arthritis. Lancet (london, England) 376(9746):1094-1108. https://doi.org/10.1016/ s0140-6736(10)60826-4

Strusberg I, Mendelberg RC, Serra HA, Strusberg AM (2002) Influence of weather conditions on rheumatic pain. J Rheumatol $29(2): 335-338$
Sung KC (2006) Seasonal variation of C-reactive protein in apparently healthy Koreans. Int J Cardiol 107(3):338-342. https://doi.org/10. 1016/j.ijcard.2005.03.045

Terao C, Hashimoto M, Furu M, Nakabo S, Ohmura K, Nakashima R, et al. (2014) Inverse association between air pressure and rheumatoid arthritis synovitis. PLoS One. 9 (1):e85376. https://doi.org/ 10.1371/journal.pone.0085376

Tobias A, Armstrong B, Zuza I, Gasparrini A, Linares C, Diaz J (2012) Mortality on extreme heat days using official thresholds in Spain: a multi-city time series analysis. BMC Public Health 12:133. https://doi.org/10.1186/1471-2458-12-133

Vergés J, Montell E, Tomàs E, Cumelles G, Castañeda G, Marti N et al (2004) Weather conditions can influence rheumatic diseases. Proc West Pharmacol Soc 47:134-136

Vicedo-Cabrera AM, Forsberg B, Tobias A, Zanobetti A, Schwartz J, Armstrong B et al (2016) Associations of inter- and intraday temperature change with mortality. Am J Epidemiol 183(4):286-293. https://doi.org/10.1093/aje/kwv205

Wang B, Chai G, Sha Y, Zha Q, Su Y, Gao Y (2021) Impact of ambient temperature on cardiovascular disease hospital admissions in farmers in China's Western suburbs. Sci Total Environ 761:143254. https://doi.org/10.1016/j.scitotenv.2020.143254

Zeng P, Bengtsson C, Klareskog L, Alfredsson L (2017) Working in cold environment and risk of developing rheumatoid arthritis: results from the Swedish EIRA case-control study. RMD Open 3(2):e000488. https://doi.org/10.1136/rmdopen-2017-000488

Zeng Y, Wan Y, Yuan Z, Fang Y (2021) Healthcare-seeking behavior among Chinese older adults: patterns and predictive factors. Int J Environ Res Public Health 18(6):2969. https://doi.org/10.3390/ ijerph18062969

Zhang X, Zhang D, Jia H, Feng Q, Wang D, Liang D et al (2015) The oral and gut microbiomes are perturbed in rheumatoid arthritis and partly normalized after treatment. Nat Med 21(8):895-905. https://doi.org/10.1038/nm.3914

Zhang Y, Peng M, Wang L, Yu C (2018) Association of diurnal temperature range with daily mortality in England and Wales: a nationwide time-series study. Sci Total Environ 619-620:291-300. https://doi.org/10.1016/j.scitotenv.2017.11.056

Zhao Y, Huang Z, Wang S, Hu J, Xiao J, Li X et al (2019) Morbidity burden of respiratory diseases attributable to ambient temperature: a case study in a subtropical city in China. Environ Health 18(1):89. https://doi.org/10.1186/s12940-019-0529-8 